\title{
DERECHOS HUMANOS Y LA PANDEMIA DEL COVID-19 EN EL REINO UNIDO*
}

\author{
MERRIS AMOS \\ Catedrática de Derechos Humanos \\ Universidad Queen Mary de Londres
}

TRC, n. ${ }^{\circ} 48,2021$, pp. 125-152

ISSN 1139-5583

\begin{abstract}
SUMARIO
I. Introducción. II. La reducción del nivel de protección de los derechos humanos por periodo limitado a través de la derogación de las obligaciones del CEDH. III. El derecho a la vida: Art. 2 CEDH. IV. El tratamiento médico de los pacientes con Covid-19. V. El confinamiento. VI. Confinamiento y otros derechos humanos. VII. Acceso a la información.VIII. Suspensión del confinamiento: vigilancia y privacidad.
\end{abstract}

\section{INTRODUCCIÓN}

Esta contribución trata de proporcionar, sobre la base de trabajos académicos anteriores, algunos detalles adicionales relativos a las diferentes cuestiones de derechos humanos que ha planteado la pandemia de Covid-19 en el Reino Unido. Esta sigue siendo una situación que evoluciona con gran rapidez y cada día surgen nuevos problemas y retos en materia de derechos humanos. Al examinar esta materia, es importante que las normas nacionales de protección de los derechos humanos sean lo más claras posibles. Aquí nos centramos en exponer la normativa aplicable y, en la medida de lo posible, sugerir cómo podría aplicarse a los problemas actuales. Sin embargo, las cuestiones de derechos humanos que se plantean son múltiples $\mathrm{y}$, a menudo, nos encontramos en situaciones en las que hay que hallar un delicado equilibrio entre los derechos de una persona y los derechos de otra. Además, a

* Este artículo ha sido traducido por Mónica Martínez López-Sáez, Investigadora García-Pelayo en el Centro de Estudios Políticos y Constitucionales 
menos que una medida concreta constituya una violación grave de los derechos de un grupo numeroso de personas, no suele ser posible extraer conclusiones generales tales como que «el confinamiento actual es proporcionado» $\mathrm{o}$ «desproporcionado». Este tipo de medidas tienen diferentes impactos para diferentes grupos e individuos, y mucho dependerá, en gran medida, de las circunstancias concretas.

En una época sin precedentes, se plantean cuestiones de derechos humanos que hace unos meses eran inimaginables en el Reino Unido. Es importante recordar que existe un marco de protección de los derechos humanos, contenido en la Ley de Derechos Humanos de 1998 ( «HRA», por sus siglas en inglés) que da mayor visibilidad y mejor aplicación al Convenio Europeo de Derechos Humanos (CEDH) y al Protocolo n. ${ }^{\circ} 1$ de dicho Convenio ${ }^{1}$. Esto va acompañado de casi 20 años de jurisprudencia nacional, aunque no cabe duda de que la jurisprudencia del Tribunal Europeo de Derechos Humanos (TEDH) también sigue siendo influyente e importante y, casi siempre, es seguida por los tribunales del Reino Unido $^{2}$. Las garantías de la HRA se aplican de forma generalizada a todas las autoridades públicas y organismos privados que ejercen funciones públicas. El artículo 3 de la HRA garantiza que la legislación clave ${ }^{3}$ se interprete de forma compatible con los derechos humanos, en la medida en que sea posible hacerlo. Por último, cualquier reclamación en materia de derechos humanos debe presentarse ante un tribunal del Reino Unido, siendo en este donde se disponen los recursos más eficaces.

Este trabajo pretende abordar temáticas específicas, aunque al principio se examinan dos cuestiones generales: la posibilidad de modificar la protección de la Ley de Derechos Humanos mediante una derogación del CEDH; y el impacto de las múltiples facetas de la protección contenida en el artículo 2 del CEDH, a saber, el derecho a la vida.

\section{LA REDUCCIÓN DEL NIVEL DE PROTECCIÓN DE LOS DERECHOS HUMANOS POR PERIODO LIMITADO A TRAVÉS DE LA DEROGACIÓN DE LAS OBLIGACIONES DEL CEDH}

Gracias a la HRA, es posible cambiar el significado de los derechos del Convenio mediante la 'derogación', en virtud del Derecho internacional, del CEDH. A este respecto, la HRA es clara. El artículo 1(2) establece que los derechos del Convenio, a los que se da mayor efecto en la HRA, están sujetos a cualquier «excepción designada». El artículo 14 establece la definición de «excepción

1 Para un análisis más exhaustivo, véase Amos, M., Human Rights Law, 3. a ed., Hart, Oxford, 2021.

2 El TEDH puede dictar medidas cautelares, pero si se produce una crisis, es mucho más rápido y eficaz obtener un recurso de un tribunal del Reino Unido.

3 Incluido el Reglamento sobre la Protección de la Salud y Restricciones provocadas por el Coronavirus de 2020 . 
designada» y el artículo 16 dispone que, para aprobar una excepción designada, debe seguirse el procedimiento de control parlamentario de voto afirmativo sobre actos de Derecho derivado (affirmative procedure for secondary legislation). En resumen, debe haber una aprobación, en un plazo de 40 días, mediante una resolución tanto de la Cámara de los Comunes como de la Cámara de los Lores, por lo que el Parlamento debe estar reunido ${ }^{4}$.

El artículo 15 del CEDH establece los elementos que deben cumplirse para que haya una excepción válida ${ }^{5}$. El artículo 15 no es una de las disposiciones del Convenio a los que la HRA da mayor efecto, aunque la Cámara de los Lores aceptó en su sentencia en el caso $A v S S H D^{6}$ que es el examen que debe aplicarse para determinar la legalidad de cualquier instrumento de derogación. Hasta la fecha, el Reino Unido no ha tenido una experiencia positiva con las excepciones en virtud de la HRA. La única excepción que se ha introducido durante la vigencia de la HRA fue anulada por la Cámara de los Lores y, mucho más tarde, por el $\mathrm{TEDH}^{7}$, precisamente por no superar el examen del artículo 15. Se consideró que medidas tales como la detención indefinida sin juicio de presuntos terroristas extranjeros, no eran «estrictamente necesarias» por las exigencias de la situación posterior al 11 de septiembre en el Reino Unido 8

Es posible una derogación de la HRA y del CEDH, pero, dadas las excepciones que contiene el propio Convenio (y también de la HRA) para hacer frente a este tipo de crisis, no resulta necesaria. En el momento de redactar esta aportación, Albania, Armenia, Estonia, Georgia, Letonia, Macedonia del Norte, Moldavia y Rumanía han notificado excepciones? ${ }^{9}$ Teniendo en cuenta las medidas adoptadas, algunos otros Estados, entre ellos Hungría, deberían haber notificado excepciones. Italia, España y Francia no han notificado excepción alguna.

Algunos autores han argumentado que el Reino Unido ya debería haber hecho una excepción para facilitar la Ley de Coronavirus de 2020 y la legislación secundaria que la acompaña ${ }^{10}$. Esto se basa en la suposición de que la Ley constituye una restricción de la libertad, que compromete el artículo 5, e interfiere de forma desproporcionada con una amalgama de derechos, incluidos los reconocidos en los artículos 8 a 14. En los párrafos siguientes y en el apartado segundo de esta nota se analiza con más detalle si las medidas actuales infringen o pueden infringir estas garantías.

4 En el momento de redactar este trabajo, está previsto que se reanude como Parlamento 'virtual-híbrido' el 21 de abril de 2020.

5 Estos se examinan con detalle por GREENE, A., https://strasbourgobservers.com/2020/04/01/statesshould-declare-a-state-of-emergency-using-article-15-echr-to-confront-the-coronavirus-pandemic/

6 [2004] UKHL 56.

7 A v United Kingdom, n. ${ }^{\circ}$ de recurso 3455/05, 19 Febrero 2009.

8 A $v$ Secretary of State for the Home Department [2004] UKHL 56.

9 https://www.coe.int/en/web/conventions/full-list/-/conventions/webContent/62111354

10 Me remito, de nuevo, a las consideraciones de Greene, op.cit. y DzeHTSiarou, K., https://strasbourgobservers.com/2020/03/27/covid-19-and-the-european-convention-on-human-rights/ 
Desde el punto de vista jurídico, el peligro de una derogación o excepción en este contexto es que eliminaría la protección de la Ley de Derechos Humanos de quienes sufren un impacto negativo desproporcionado por las medidas adoptadas. Aunque la pandemia nos afecta a todos, no lo hace por igual y es muy importante que los más vulnerables tengan acceso a la protección de los derechos humanos para hacer frente a los efectos más devastadores de la pandemia. Aunque no es posible derogar los artículos 2 y 3 , sí es posible derogar el artículo 8 (vida privada y familiar), el artículo 10 (libertad de expresión) y, lo que es más preocupante, el artículo 14, que protege a los grupos vulnerables ante tratos discriminatorios. Aunque la normativa vinculante y programática actual (leyes, reglamentos y directrices) parecen lo suficientemente flexibles como para atender a los grupos más desfavorecidos, la HRA proporciona un importante respaldo de protección y seguridad jurídica. Además, el gobierno ha manifestado su compromiso de respetar las garantías de la HRA durante toda la crisis. Durante la tramitación del proyecto de ley sobre el coronavirus en la Cámara de los Lores, Lord Bethell ${ }^{11}$ declaró lo siguiente: «El Gobierno está comprometido al 100\% con la protección y el respeto de los derechos humanos. El Reino Unido se mantiene fiel a su larga tradición de defensa de los derechos y las libertades a nivel nacional y de cumplir nuestros compromisos en materia de derechos humanos. Esto no cambiará. Contamos con una sólida protección de los derechos humanos, con un sistema constitucional y jurídico completo y consolidado. La Ley de Derechos Humanos de 1998 da mayor vigencia a los derechos y libertades contenidos en el Convenio Europeo de Derechos Humanos. Nada en este proyecto de ley contradice eso. Quiero tranquilizar a varios oradores... no hay nada en esta Ley que permita al Gobierno incumplir o inaplicar la Ley de Derechos Humanos o la Ley de Igualdad. El propio proyecto de ley cumple plenamente con la Ley de Derechos Humanos y el Gobierno lo ha certificado en el texto del proyecto; de hecho, yo mismo lo he firmado de acuerdo con el artículo 19. Todo ejercicio del poder, en virtud del artículo 6 de la Ley de Derechos Humanos, por parte de una autoridad pública, establecida como tal en este proyecto de ley, debe, a su vez, cumplir con la Ley de Derechos Humanos. Además, aseguro a la Cámara que, en todo momento, este Gobierno actuará de forma proporcionada ${ }^{12}$.

Desde el punto de vista político y estratégico, la derogación plantea otra serie de dificultades. El primero de estos obstáculos resulta ser el mensaje y discurso político. Decirle a la ciudadanía británica que sus derechos humanos van a ser suspendidos, incluso si se trata de una suspensión limitada, intensifica aún más la actual tormenta de pánico y confusión. Que el Reino Unido suspenda, cuando Francia, Italia o España no lo han hecho, también envía el mensaje equivocado a los Estados menos liberales, sobre todo cuando se trata de una situación

11 Subsecretario de Estado Parlamentario, Ministerio de Salud y Asuntos Sociales.

12 HL Deb 25 March 2020, Vol 802, Col 1778. 
que cambia rápidamente, que no tiene un horizonte claro ni puede vislumbrarse un final cercano, y a pesar de ello nuevas derogaciones o estados de excepción podrían aprobarse por el Parlamento cada mes o cada par de semanas. Además, una vez que la amenaza inmediata y abrumadora para la vida haya terminado (o, al menos disminuido), es probable que sean necesarias graves injerencias en la vida privada, como la vigilancia epidemiológica y el acceso a la historia clínica, para permitir algún tipo de vida normal. Aunque muchos podrían aceptar la limitación del derecho a la vida privada, ante las circunstancias actuales, el suspender indefinidamente este derecho para facilitar un retorno a la normalidad, acarrea numerosos riesgos.

\section{EL DERECHO A LA VIDA: ART. 2 CEDH}

El propósito de este estudio es explorar las cuestiones que plantea la pandemia del Covid-19 de la forma más concreta posible, pero, antes de ello, es importante examinar un derecho humano primordial: el derecho a la vida, reconocido en el artículo 2 del CEDH.

Tanto los tribunales del Reino Unido como el propio TEDH han interpretado que el artículo 2 incluye el deber de no quitar la vida (obligación negativa), en algunas circunstancias el deber de tomar medidas para evitar que se quite la vida (obligación positiva) y, como parte de este último, el deber de investigar las circunstancias que rodean una muerte (obligación adicional de investigar). El derecho a la vida de todos está protegido y es inherente a la condición humana que todos compartimos ${ }^{13}$, siendo ilícito, en virtud del artículo 2, contraponer el valor de una vida al de otra ${ }^{14}$.

\section{Obligación positiva de proteger}

Los dos deberes más importantes en el contexto de la pandemia provocada por el SARS-CoV-2 son el deber positivo de proteger y el deber de investigar. Los orígenes del deber positivo se encuentran en la sentencia del TEDH del asunto Osman ${ }^{15}$, doctrina acogida por la Cámara de los Lores en la sentencia del asunto Officer $L^{16}$, según la cual debe determinarse si la autoridad pública conocía o debería haber conocido la existencia de un riesgo real e inmediato para la vida, y si no adoptó medidas, en el ámbito de sus competencias, siendo razonablemente previsible que podrían haber evitado ese riesgo. En este caso, el riesgo para la vida es

$13 R v$ Director of Public Prosecutions, ex p Pretty [2001] UKKHL 61 per Lord Hope at [87].

14 Re A (Children) (Conjoined Twins) [2001] Fam 147.

15 Osman v UK (1997) 29 EHRR 245.

16 [2007] UKHL 36. 
evidente $^{17}$. El 16 de marzo de 2020, el informe elaborado por el Imperial College concluyó que, si se seguía una estrategia de mitigación, en lugar de supresión, del virus, podría dar lugar a 250.000 muertes en Gran Bretaña ${ }^{18}$. El confinamiento fue anunciado por el gobierno del Reino Unido el 23 de marzo de 2020 y entró en vigor el 26 de marzo de 2020.

El conocimiento también es clave, por lo que el deber principal del estado es tomar medidas razonables para evitar los riesgos conocidos. Visto en retrospectiva, ahora está bien claro que hubo un retraso innecesario en tomar las medidas necesarias, encabezado por una estrategia inicial de inmunidad de rebaño y de protección de los vulnerables. A pesar de ello, el confinamiento entró en vigor el 26 de marzo siguiendo la trayectoria de países como Italia, España y Francia. El confinamiento domiciliario no fue tan estricto como en otros estados, por lo que aún podrían plantearse cuestiones sobre si constituía una respuesta razonable a la amenaza para la vida y si debería haberse llevado a cabo con restricciones más estrictas. En el apartado que trata específicamente el confinamiento, se examinarán estas cuestiones con más detalle.

\section{Deber de investigar}

Tal y como figura en el artículo 2, existe la obligación de investigar cuando exista y pueda defenderse que ha habido una violación del artículo $2^{19}$. El tipo de investigación requerida variará en función de las circunstancias, pero cuanto más graves sean los hechos, más intenso deberá ser el proceso de indagación ${ }^{20}$.

No cabe duda de que, a largo plazo, debe llevarse a cabo una investigación pública a gran escala sobre la pandemia del Covid-19 y la respuesta a la misma, debiendo ser el propio gobierno el que decida iniciarla de oficio, y no como respuesta a una reclamación en virtud de la HRA. Todas las cuestiones que se pueden plantear son trágicas, pero algunas son más adecuadas para una investigación de este tipo que las reclamaciones individuales sobre el incumplimiento del deber de proteger la vida ${ }^{21}$. Entre ellas se encuentran: la falta de preparación de las instituciones para enfrentarse a una pandemia ${ }^{22}$; el retraso en la respuesta a pesar de

17 Véase Mavronicola, N., https://strasbourgobservers.com/2020/04/07/positive-obligations-in-crisis/

18 Equipo de respuesta de COVID-19 del Imperial College, 16 de Marzo de 2020. https://www.imperial.ac.uk/media/imperial-college/medicine/sph/ide/gida-fellowships/Imperial-College-COVID19-NPI-modelling-16-03-2020.pdf

19 R. (Gentle) $v$ The Prime Minister [2008] UKHL 20.

$20 R$. (Amin) $v$ Secretary of State for the Home Department [2003] UKHL 51.

21 Las acciones colectivas no son posibles en el marco de la HRA y la prueba de la víctima de la sección 7 requiere que las víctimas sean sujetos directamente afectados.

22 El NHS no superó una «importante prueba intergubernamental de su capacidad para hacer frente a una pandemia grave» llevada a cabo en octubre 2016, Gardner, B. y Nuki, P., The Telegraph, 28 de marzo de 2020 . 
las advertencias de China e Italia; las estrategias iniciales de 'inmunidad de rebaño' y medidas de protección personal; la lentitud en realizar pruebas al personal del sistema nacional de salud, permitiéndoles volver al trabajo; y la lentitud en realizar pruebas a la población en general ${ }^{23}$.

Otras cuestiones del artículo 2, como los fallos inmediatos en la investigación, son más urgentes y requieren una resolución más rápida, posiblemente en sede judicial. Estas cuestiones se analizan en los apartados siguientes.

\section{EL TRATAMIENTO MÉDICO DE LOS PACIENTES CON COVID-19}

\section{Escasez de equipos de protección individual (EPI)}

El personal sanitario del sistema nacional de salud, el personal de las residencias de ancianos y otros, como los farmacéuticos y los trabajadores del transporte público, se quejaron constantemente de que no disponían de equipos de protección individual (EPI) adecuados y eficaces que les permitieran realizar su trabajo sin riesgo de contraer el virus ${ }^{24}$. En el momento de redactarse esta contribución académica, hay numerosos informes sobre médicos, enfermeras, conductores de autobús y otras personas que han perdido trágicamente la vida por haberse contagiado de Covid-19 en el desempeño de su trabajo.

El artículo 2 impone al Estado la obligación positiva de proporcionar este equipo y, en la sentencia del asunto Smith y Ellis ${ }^{25}$, el Tribunal Supremo estableció un argumento similar. En este caso, se trataba de desestimar una demanda en la que se alegaba que el Ministerio de Defensa había incumplido su obligación de tomar las medidas adecuadas para proteger la vida, proporcionando un equipo blindado adecuado para que lo utilizaran sus soldados en servicio activo en Irak. La decisión mayoritaria confirmó que este tipo de fallos no son inmunes al escrutinio del artículo 2, pero matizó que el contexto es importante en estos supuestos. Sostuvo que los militares deben recibir la misma protección contra el riesgo de muerte y lesiones que los miembros de la policía, los bomberos y otros servicios de emergencia mediante la impartición de formación y el suministro de equipamiento adecuado. Sin embargo, concluyó que la situación era diferente cuando el militar pasaba del reclutamiento y la formación a las operaciones en el servicio activo, observando, para

23 Aunque en el momento de redactar este trabajo existen dudas sobre la precisión de las pruebas disponibles y esto es, por supuesto, un motivo de retraso.

24 CAmpbell, D., «Lack of surgical gowns for medics 'a disaster in wating», The Guardian, 9 de abril 2020; MAY, L., «Doctors lacking protective equipment are being bullied and shamed into treating coronavirus patients», The Daily Mail, 7 de abril de 2020.

25 Smith and Ellis v Ministry of Defence [2013] UKSC 41. 
estos casos, que se requería una pauta más amplia para determinar quiénes se consideraban que estaban 'sobre el terreno'.

La mayoría del Tribunal concluyó que las obligaciones positivas en este contexto deben evitarse, si son poco realistas o son desproporcionadas. A su vez, concluyó que el Estado «deberá cumplir esas obligaciones cuando sea razonable esperar que el individuo reciba la protección del artículo». La mayoría concluyó que las reclamaciones en virtud del artículo 2 no debían ser anuladas, sino que debían ir a juicio, con la advertencia de que el juez de primera instancia deberá conceder un amplio margen de discrecionalidad a la hora de juzgar las medidas tomadas por los responsables.

Con respecto a los EPI en la pandemia de Covid-19, puede ser que la escasez mundial signifique que los suministros simplemente no están disponibles, a pesar de todos los esfuerzos realizados. La situación también se complica por la presencia de otro deber positivo del artículo 2: el relativo a que el sistema nacional de salud debe tratar a un paciente cuando el tratamiento es lo mejor para él/ella. En este caso, existen obligaciones positivas contradictorias que recaen sobre los responsables sanitarios. En primer lugar, el deber de tomar medidas razonables, dentro del ámbito de sus competencias, para evitar el riesgo para la vida que supone exigir a su personal que trate a pacientes con Covid-19 sin equipo de protección. En segundo lugar, el deber de tomar medidas razonables, dentro del ámbito de sus competencias, para tratar a un paciente cuando la vida está en peligro (suponiendo que el tratamiento siga siendo en el mejor interés del paciente). El equilibrio dependerá en gran medida de los hechos de cada caso concreto. Podría argumentarse que no es razonable, ni está dentro del ámbito de las competencias del sistema nacional de salud, obligar a un empleado del mismo que no padece Covid-19 a tratar a pacientes con Covid-19 sin la protección adecuada. Pero, ¿podría ser razonable obligar al personal sanitario que se ha recuperado y es inmune, aunque se trate de un grupo pequeño de personas, dados los problemas que ha habido con las pruebas de detección?

Es poco probable que una reclamación urgente de la HRA, argumentando el incumplimiento del deber sustantivo de proteger la vida debido a la falta de EPI, hubiera facilitado la obtención del EPI necesario si no era posible conseguirlo. Lo que sería más útil en ese momento sería una reclamación que desencadenara una investigación de emergencia, para que los esfuerzos del gobierno se expusieran al escrutinio y crítica de la ciudadanía.

\section{Asignación de (y toma de decisiones sobre) el tratamiento}

La Asociación Médica Británica ha publicado una nota orientativa sobre las cuestiones éticas que plantea el Covid-19 ${ }^{26}$. En ella se afirma lo siguiente: 
«Aunque es probable que los médicos encuentren estas decisiones difíciles, si hay una capacidad radicalmente reducida para satisfacer todas las necesidades sanitarias graves, resulta tanto lícito como ético que un médico, siguiendo políticas adecuadas de priorización, deniegue un tratamiento que podría salvarle la vida a una persona cuando otra persona tenga una prioridad más elevada para recibir el tratamiento disponible» ${ }^{27}$.

A medida que la pandemia se ha ido desarrollando, hemos observado como la demanda de recursos y personal puede superar a la oferta ${ }^{28}$ y que los comités de ética de cada hospital han tenido que decidir quién tiene prioridad en los tratamientos vinculados al Covid-1929. El 12 de abril de 2020, el Financial Times informó de que el sistema nacional de salud había adoptado un sistema de puntuación para decidir qué pacientes recibirían cuidados críticos, aunque su uso fue rápidamente desmentido ${ }^{30}$. Además, en ese momento, el sistema aún no estaba al máximo de su capacidad y no se había producido un racionamiento de los cuidados críticos, aunque también se ha informado ampliamente de que muchos residentes de residencias de ancianos que sufrieron el Covid-19 no estaban siendo trasladados al hospital y estaban muriendo en la residencia. También había numerosas muertes de personas mayores y estas cifras no formaban parte del recuento de los primeros informes oficiales.

Determinar lo que exige el artículo 2 es difícil en este caso, tanto desde el punto de vista moral como jurídico, y la situación no tiene precedentes. En anteriores sentencias de la HRA, la denegación o la interrupción del tratamiento de las personas gravemente discapacitadas o en estado vegetativo permanente se ha caracterizado como una omisión y no como una privación intencionada de la vida. En estos casos sólo existe la obligación de tratar a un paciente que no tiene capacidad para aceptar o rechazar el tratamiento cuando este redunda en su interés ${ }^{31}$. Sin embargo, si el tratamiento atiende al interés superior del paciente, cualquier fallo en el tratamiento constituirá una violación del artículo 2: «Por lo tanto, el artículo 2 impone una obligación positiva de administrar un tratamiento de mantenimiento de la vida, en circunstancias en las que, según una opinión médica responsable, dicho tratamiento resulta

27 Sobre esta temática, cfr. Thomas, G., Gollop, K. y Roper, S., «Covid-19: Allocation and withdrawal of ventilation — the urgent need for a national policy», http://ukmedicaldecisionlawblog.co.uk/ rss-feed/119-covid-19-allocation-and-withdrawal-of-ventilation-the-urgent-need-for-a-national-policy

28 DAviES, R. y RANKIN, J., «NHS faces shortfall of ventilators as manufacturers struggle», The Guardian, 3 de abril de 2020 .

29 Chisholm, J., «Doctors will have to choose who gets life saving treatment», The Guardian 1 de abril de 2020 .

30 https://www.ft.com/content/d738b2c6-000a-421b-9dbd-f85e6b333684? sharetype=blocked

31 NHS Trust A v Mrs M [2001] 2 WLR 942, [37]. Véase también el asunto previo a la entrada en vigor de la Ley de Derechos Humanos, en el que se llegó a la misma conclusión: Airedale NHS Trust $v$ Bland [1993] AC 789, per Lord Goff at 867 and Lord Brown Wilkinson at 884-85; y el asunto posterior a su vigencia, Aintree University Hospitals NHS Foundation Trust v James [2013] UKSC 67. 
ser lo mejor para el paciente, pero no impone una obligación absoluta de tratar, si dicho tratamiento resultara ineficaz» ${ }^{32}$.

Otra sentencia relevante es la del caso $D^{33}$, en la que el juez Cazalet llegó a la conclusión de que el tratamiento del Sr. I, que incluiría la no reanimación en caso de insuficiencia respiratoria y/o cardíaca y/o parada, con cuidados paliativos para aliviar su sufrimiento y permitir que su vida terminara pacíficamente con dignidad, era lo que más le convenía a I: «Teniendo en cuenta la mínima calidad de vida que le queda al Sr. I en el corto periodo de vida que le queda debido a su irreversible y empeorada condición pulmonar, debo sopesar, desde el punto de vista que asumiría el propio Sr. I, cualquier posible extensión limitada a corto plazo de vida resultante de la ventilación mecánica frente al creciente dolor y sufrimiento causado por dicha ventilación mecánica adicional...Considero que el análisis minucioso y cuidadoso del camino a seguir a través de un tratamiento paliativo completo, tal y como defienden los pediatras en la declaración solicitada, es lo mejor para I».

Tampoco existe la obligación de tratar cuando hacerlo expondría al paciente a un trato inhumano o degradante, lo que infringiría el artículo 3 del $\mathrm{CEDH}^{34}$.

La 'futilidad' del tratamiento ha sido el criterio adoptado por la Asociación Médica Británica, aunque lo expresan, en sentido positivo, como la «capacidad de beneficiarse rápidamente». En las circunstancias actuales, un tratamiento que antes no se consideraba inútil puede pasar a serlo de repente, si se agotan los recursos para tratar a todo el mundo. Sin embargo, el éxito de una reclamación en la que se afirma que un organismo vinculado al sistema nacional de salud incumple el deber positivo del artículo 2 de proteger la vida dependerá, en gran medida, de las circunstancias del caso. A corto plazo, lo más probable es que prosperen las demandas por incumplimiento del deber de investigación del artículo 2, obligando a revelar las medidas utilizadas por los distintos centros para determinar el tratamiento. A largo plazo, debe haber una investigación conforme al artículo 2 que se centre en cómo se ha llegado a esta situación en un país reconocido como la sexta economía del mundo.

Cualquier tipo de priorización de los pacientes de Covid-19 para determinar el acceso a los cuidados críticos también tiene el potencial de discriminar a ciertos grupos. Esto también lo ha reconocido la Asociación Médica Británica en su guía, en la que afirma que durante el pico de la pandemia, es probable que los médicos «tengan que evaluar la idoneidad de una persona para el tratamiento sobre la base de un análisis fundamentado en la capacidad de beneficiarse rápidamente». En este sentido, el artículo 14 del CEDH es clave. En él se establece que

32 NHS Trust A v Mrs M ibid, [37]. See also Wv M [2011] EWHC 2443 (Fam) que se refería a una propuesta para retirar la nutrición e hidratación artificial a un paciente en estado de mínima conciencia. Véase también An NHS Trust v DJ [2012] EWHC 3524 (COP).

33 A National Health Service Trust v D [2000] 2 FLR 677.

34 R. (Burke) v General Medical Council [2005] EWCA Civ 1003 at [39]. 
los derechos del Convenio deben garantizarse sin discriminación de ningún tipo. La aplicación del artículo 14 a una situación de hecho es compleja y nos limitamos, en el presente artículo, a resumir las partes que consideramos más relevantes. En el caso de la pandemia de Covid-19, los hechos entran en el ámbito de aplicación del artículo 2, y existe tanto una discriminación directa (posiblemente contra los residentes de las residencias) como una discriminación indirecta (resultante de cualquier sistema de 'puntuación' u otros medios vinculados a la priorización de cualquier tipo de atención médica). Tal y como reconoce la Asociación Médica Británica, entre los grupos desfavorecidos se encuentran las personas mayores y las que padecen enfermedades de larga duración. En virtud del artículo 14, estos son motivos de discriminación prohibidos.

Por lo tanto, la decisión tendría que estar justificada, ya que el derecho reconocido por el artículo 14 no es un derecho absoluto. En su sentencia en el asunto Steinfel ${ }^{35}$, el Tribunal Supremo sostuvo que el criterio justificativo y el test de proporcionalidad de las medidas en relación con los derechos dispuestos en el Convenio, como el artículo 14, son aquellos resumidos en el asunto Quila: «(a) ¿Es el objetivo legislativo (objetivo legítimo) lo suficientemente importante como para justificar la limitación de un derecho fundamental? (b) ¿Están las medidas que se han diseñado para cumplirlo racional y razonablemente conectadas con dicho objetivo? (c) ¿Son estas medidas las justas y necesarias para lograrlo? y (d) ¿Logran un equilibrio justo entre los derechos del individuo y los intereses de la comunidad?» ${ }^{36}$.

El objetivo legítimo identificado en este caso sería probablemente la preservación de los recursos para tratar a los que tienen una mayor esperanza de vida y a aquellos para los que el tratamiento no es «inútil». En su guía, la Asociación Médica Británica se refiere únicamente a la Ley de Igualdad de 2010 y afirma que la justificación sería «cumplir con el requisito de utilizar los recursos limitados del sistema nacional de salud de la mejor manera posible». También es importante tener en cuenta que un tribunal puede considerar que una reclamación de este tipo no es justiciable e incluso, si procediera, cuando los factores económicos se plantean como una justificación, los tribunales son mucho más propensos a confirmar la decisión de la autoridad competente ${ }^{37}$.

\section{EL CONFINAMIENTO}

Los numerosos reglamentos de 2020 sobre la Protección de la Salud y Restricciones provocadas por el Coronavirus que impusieron, en Inglaterra, el

35 R. (Steinfeld) v Secretary of State for International Development [2018] UKSC 32.

36 [41] Steinfeld, quoting from R. (Aguilar Quila) v Secretary of State for the Home Department [2011] UKSC 45, [2012] AC 621 at [45].

37 Brewster v Northern Ireland Local Government Officer's Superannuation Committee [2017] UKSC 8. 
confinamiento domiciliario entraron en vigor el 26 de marzo de $2020^{38}$, aunque esta medida ya había sido anunciada el 23 de marzo de 2020. Se impusieron una serie de restricciones, incluidas el cierre de determinados locales ${ }^{39}$, restricciones de las reuniones sociales ${ }^{40}$ y restricciones de los desplazamientos y libre circulación ${ }^{41}$. En resumen, ninguna persona podía abandonar el lugar de residencia sin una causa justificada. Se enumeran en dicho instrumento jurídico una serie de razones válidas («excusas razonables», por su traducción literal del inglés), pero la lista no es exhaustiva. También se podían encontrar explicaciones adicionales en las directrices gubernamentales ${ }^{42}$. El reglamento sexto ha sido el que ha suscitado más crítica, sobre todo debido a su aplicación excesivamente entusiasta y, en algunos casos, debido a prácticas policiales ilegales, so pretexto de asegurar su cumplimiento ${ }^{43}$.

Se plantean una serie de cuestiones de derechos humanos como resultado del confinamiento y es importante identificarlas ya que las leyes que regulan este tipo de medida restrictiva del ejercicio de los derechos, así como el significado de «causa justificada», deben interpretarse y aplicarse de manera coherente con los derechos humanos, en la medida en que sea posible hacerlo ${ }^{44}$.

\section{Confinamientos y privación de la libertad personal}

El artículo 5 del CEDH regula las privaciones de libertad y reconoce que el derecho a la libertad no es un derecho humano absoluto sino limitado. Para que se aplique el artículo 5, primero debe establecerse que existe una 'privación de libertad', concepto jurídico que, como veremos, tiene un significado autónomo. Basándose en la autoridad del TEDH, en el asunto Cheshire West ${ }^{45}$ una mayoría del Tribunal Supremo sostuvo que deben estar presentes tres elementos para fundamentar que existe una privación de libertad: (a) el elemento objetivo del

38 Las mismas medidas se tomaron en relación con Gales, Escocia e Irlanda del Norte. Para más detalles, véase el documento informativo de la Comisión Mixta de Derechos Humanos, de 8 de abril 2020 https://publications.parliament.uk/pa/jt5801/jtselect/jtrights/correspondence/Chairs-briefing-paper-regarding-Health-Protection-Coronavirus-Restrictions-England-Regulation-2020.pdf

39 Reglamento n. 4.

40 Reglamento n. 7. Véase también las reflexiones de MEAD, D., «The human rights implications of the ban on gatherings in Regulation 7»: https://protestmatters.wordpress.com/2020/04/10/the-governmentsresponse-to-covid-19-the-human-rights-implications-of-the-ban-on-gatherings-in-regulation-7/

41 Reglamento n. 6.

42 https://www.gov.uk/government/publications/coronavirus-outbreak-faqs-what-you-can-andcant-do/coronavirus-outbreak-faqs-what-you-can-and-cant-do

43 Véase, por ejemplo, la anulación de una multa de 660 libras esterlinas cuando una mujer fue acusada erróneamente de un delito. DeArden, L., «Coronavirus: Woman fined £660», The Independent, 3 April 2020.

44 Sección 3, HRA. En caso de que surjan problemas, ésta es, con mucho, la vía más rápida de protección y no requiere la intervención del Parlamento.

45 Cheshire West E Chester Council v P [2014] UKSC 19, [2014] AC 896; P and Q (by their litigation friend the Official Solicitor) v Surrey County Council [2011] EWCA Civ 190, [2012] 2 WLR 1056. 
confinamiento de una persona en un lugar determinado y limitado durante un periodo significativo de tiempo; (b) el elemento subjetivo adicional de que la persona no haya dado su consentimiento válido a someterse al confinamiento en cuestión; y (c) que el confinamiento sea imputable al Estado ${ }^{46}$. Lady Hale señaló que la «prueba de fuego» para una privación objetiva de libertad era que el individuo estuviera sometido a una supervisión y un control constantes y que no pudiera salir de manera libre y espontánea ${ }^{47}$.

En la sentencia del asunto Austin ${ }^{48}$, la Cámara de los Lores sostuvo que también era importante tener en cuenta la finalidad de la medida en cuestión: «Si le otorgamos relevancia a la finalidad de una medida limitativa de los derechos, debe ser para permitir encontrar un equilibrio entre lo que la restricción pretende conseguir y los intereses del individuo ${ }^{49}$. Sin embargo, esto fue expresamente rechazado por el TEDH en su sentencia en Austin c. Reino Unido y rechazado por la mayoría del Tribunal Supremo en su sentencia en Cheshire West, aunque el contexto sigue siendo importante ${ }^{50}$. En su sentencia del caso Austin c. Reino Unido, el TEDH sostuvo que la finalidad de la medida en cuestión no era relevante y no tenía relación con la cuestión relativa a si la persona había sido privada de su libertad «aunque sí que podría ser relevante para el posterior examen de si la medida de privación de libertad estaba justificada» ${ }^{51}$. A pesar de lo anterior, el contexto sí resulta ser un elemento considerable, por lo que el TEDH también observó que: «la exigencia de tener en cuenta el 'tipo' y la 'forma de aplicación' de la medida en cuestión [...] permite considerar el contexto y las circunstancias específicas que rodean a otros tipos de restricción de la libertad personal distintos del confinamiento carcelario. En efecto, el contexto en el que se adopta la medida es un factor importante que debe tenerse en cuenta, ya que en la sociedad moderna se producen habitualmente situaciones en las que los ciudadanos pueden verse obligados a soportar restricciones a la libertad de circulación o a la libertad personal en general en aras del bien común [...] En cada caso, el apartado 1 del artículo 5 debe interpretarse teniendo en cuenta el contexto específico en el que se emplean estas técnicas, así como las responsabilidades vinculadas al cumplimiento del deber de mantener el orden y proteger al público por parte de la policía, tal y como se les exige tanto en virtud del derecho nacional como del Convenio $»^{52}$.

La distinción entre privación de libertad y restricción de la libertad de movimiento es que esta última entra en el ámbito de aplicación del artículo 2 del

46 Per Lady Hale at [37] in reliance upon Storck v Germany (2005) 43 EHRR 96. See also Re D (A Child) [2019] UKSC 42, [2019] 1 WLR 5403 at [1] per Lady Hale.

47 At [49].

48 Austin v Commissioner of Police of the Metropolis [2009] UKHL 5.

49 Ibid, per Lord Hope at [27].

50 [43] per Lady Hale, Cheshire West.

51 [58], Austin v UK, Appl, 39692/09, 15 March 2012.

52 [59]-[60]. 
Protocolo n. ${ }^{\circ} 4$ del CEDH en vez del artículo $5^{53}$. La distinción es, por tanto, de grado o intensidad de las restricciones y no de naturaleza o contenido esencial. Es necesario partir de la situación concreta o real del individuo en cuestión y tener en cuenta una serie de criterios como la tipología, la duración, los efectos y la forma de aplicación de la medida en cuestión. También hay que tener en cuenta el efecto acumulativo de las distintas restricciones ${ }^{54}$.

Para la mayoría de las personas, el confinamiento no satisface los criterios ni el umbral establecidos para la privación de libertad, teniendo en cuenta el contexto y la ausencia de 'supervisión y control constantes'. Es este elemento, según la sentencia del asunto $J J^{55}$, el que distingue el confinamiento de la restricción de la libertad en el contexto del terrorismo con las llamadas control orders. En este caso, los que eran vigilados debían permanecer en su domicilio en todo momento, salvo durante un período de seis horas entre las 10.00 y las 16.00 horas. Las visitas debían ser autorizadas por el Ministerio del Interior, durante las seis horas en que se les permitía salir, estaban confinados en zonas urbanas restringidas y se les prohibía reunirse con cualquier persona que no hubiera sido autorizada por el Ministerio del Interior. La mayoría de la Cámara de los Lores concluyó que las restricciones equivalían a una privación de libertad. Lord Bingham observó lo siguiente: «El efecto del toque de queda de 18 horas, unido a la exclusión efectiva de las visitas sociales, significaba que las personas controladas se encontraban, en la práctica, en un régimen de aislamiento durante este largo período todos los días por una duración indefinida, con muy pocas oportunidades de contacto con el mundo exterior [...] El área abierta a ellos durante sus seis horas sin toque de queda era de una duración inaceptable [...] Pero se encontraban [...] en una zona desconocida donde no tenían familia, amigos ni contactos [...] Sus vidas estaban totalmente reguladas por el Ministerio del Interior, como la estaría la de un preso» ${ }^{56}$.

El confinamiento domiciliario que vivieron los ingleses se aproxima más a los hechos de la sentencia del asunto $E^{57}$, pues, en este, el toque de queda tenía una duración de 12 horas, desde las 7 de la mañana hasta las 7 de la tarde, y el espacio de confinamiento era el propio domicilio del controlado, en una parte de Londres que conocía bien, y vivía en su casa con su mujer y su familia. No existían restricciones geográficas durante las horas en que no había toque de queda y no se le prohibía relacionarse con personas concretas. Se concluyó que esto no equivalía a una privación de libertad en el sentido del artículo 5.

53 Secretary of State for the Home Department $v$ Mental Health Review Tribunal 'PH' [2002] EWCA Civ $1868,[14]$.

54 PH, ibid, [15].

55 Secretary of State for the Home Department v JJ [2007] UKHL 45.

56 Ibid, [24].

57 Secretary of State for the Home Department v E [2007] UKHL 47, [2008] 1 AC 499. 


\section{Confinamiento y artículo 5.1(e) $\mathrm{CEDH}$ : detenciones para evitar la propagación de enfermedades infecciosas}

Si el confinamiento per se equivale o no a una privación de libertad es una cuestión finalmente aclarada y para algunos, que pueden estar bajo constante vigilancia policial, es posible que el confinamiento sí equivalga a una privación de libertad. Por lo tanto, es importante considerar lo que exige el artículo 5, que reconoce que el derecho a la libertad es un derecho limitado y la privación de libertad, mediante internamiento o confinamiento domiciliario, es posible en virtud de la letra e) del apartado 1 del artículo 5, para prevenir la propagación de enfermedades infecciosas. Además del sentido literal de este precepto, hay dos requisitos primordiales. El primer requisito primordial es que toda privación de libertad debe ajustarse a un procedimiento prescrito por la ley. El segundo requisito es que debe ser ajustarse a derecho ${ }^{58}$. Si se cumplen estos requisitos, el apartado 1 del artículo 5 no delimita el período durante el cual una persona puede ser detenida ${ }^{59}$.

Se presume que la privación de libertad en el contexto de la pandemia del Covid-19 es conforme a un procedimiento prescrito por la ley ${ }^{60}$. Con respecto al segundo requisito, para ser legal, la privación de libertad debe ser lícita según el derecho interno y cumplir con los requisitos generales del Convenio. Estos se basan en el principio de que toda restricción de los derechos humanos y las libertades fundamentales debe estar prescrita por la ley. Este principio incluye los requisitos de que el derecho interno debe ser lo suficientemente accesible para el individuo y la medida debe ser lo suficientemente precisa para permitirle prever las consecuencias de la restricción. Dada la confusión en torno a lo que la gente podía y no podía hacer, y las importantes «incoherencias en la comunicación al público» sobre la nueva normativa ${ }^{61}$, no se cumple el requisito de legalidad del Convenio, estrechamente vinculado al Estado de Derecho ${ }^{62}$. Tal y como recomienda el Comité Mixto, es importante que esto se rectifique lo antes posible, no sólo para cumplir con el artículo 5, sino también para dar cumplimiento a los artículos 8 a 10 .

Suponiendo que se rectifique el mensaje confuso sobre el confinamiento, el siguiente paso es considerar el significado del artículo 5(1)(e). Dada la ausencia de pandemias recientes en el Reino Unido, y la limitada autoridad del TEDH, esto no ha sido objeto de litigio en el marco de la HRA. En el caso Enhorn contra

$58 R v$ Governor of Brockhill Prison, exp Evans (No 2) [2001] 2 AC 19.

59 Flynn v HM Advocate [2004] UKPC D1, [2004] HRLR 17.

60 Véase los Reglamento de 2020 sobre la protección de la salud, op. cit. y las medidas equivalentes en Irlanda del Norte, Escocia y Gales.

61 Comisión Mixta de Derechos Humanos, op. cit., apartado 19.

62 Un recorrido temático lo proporciona Hickman, T., Dixon, E. y Jones, R., «Coronavirus and civil liberties in the UK»: https://coronavirus.blackstonechambers.com/coronavirus-and-civil-liberties-uk/ 
Suecia ${ }^{63}$, el TEDH sostuvo que «los criterios esenciales a la hora de evaluar la 'legalidad' de la detención de una persona 'para la prevención de la propagación de enfermedades infecciosas' son si la propagación de la enfermedad infecciosa es peligrosa y un riesgo para la salud o la seguridad públicas, y si la detención de la persona infectada es el último recurso para evitar la propagación de la enfermedad, no habiendo medidas menos lesivas o, de haberlas, resultan insuficientes para salvaguardar el interés público. Cuando estos criterios dejan de cumplirse, el fundamento de la privación de libertad deja de existir» ${ }^{64}$.

Aunque, en el momento de redactar este artículo, el confinamiento de la mayoría de la población se ajusta a estos requisitos, con el paso del tiempo, y a medida que aumenta el número de personas que se someten a pruebas de inmunidad, se podrá cuestionar si el confinamiento domiciliario sigue constituyendo una medida de «último recurso», y, por tanto, si no cumple el test de necesidad $^{65}$.

\section{CONFINAMIENTO Y OTROS DERECHOS HUMANOS}

Además de la libertad, surgen otras cuestiones de derechos humanos como consecuencia del confinamiento y es importante identificarlas, ya que las leyes que regulan esta medida, incluido el significado de «causa justificada» (reasonable excuse) debe concebirse desde la perspectiva de los derechos humanos como interpretación conforme; es decir, debe interpretarse de forma coherente con los derechos humanos, en la medida en que sea posible hacerlo ${ }^{66}$. Los derechos más amenazados son el derecho al respeto a la vida privada (artículo 8), el derecho al respeto a la vida familiar (artículo 8), la libertad religiosa (artículo 9), la libertad de expresión (artículo 10) y la libertad de reunión (artículo 11).

Todos ellos son derechos con reservas, lo que significa que, al margen del artículo 14, al que se le aplica una prueba ligeramente diferente, cada uno de ellos puede ser objeto de una injerencia legal, siempre que la injerencia esté «prescrita por la ley» y sea necesaria. Como se ha analizado en la primera parte de este trabajo, la cuestión de si el confinamiento está o no «prescrito por la ley» está abierta a la duda, aunque el mensaje general de permanecer en casa es evidente. En su sentencia en el caso Gillan, Lord Bingham explicó el significado de la expresión «con arreglo a lo prescrito por la ley» de la siguiente manera: «El ejercicio del poder por parte de los funcionarios públicos, en la

63 ECtHR, n. ${ }^{\circ}$ de recurso 56529/00, 25 January 2005.

64 [44].

65 También es posible que un tribunal del Reino Unido adopte un enfoque diferente en la interpretación y aplicación del artículo 5, apartado 1, letra e), en virtud de la HRA.

66 Sección 3, HRA. cuando surgen problemas, ésta es, con mucho, la vía más rápida de protección y no requiere la intervención del Parlamento. 
medida en que afecta a miembros de la sociedad, debe estar regido por normas jurídicas claras y accesibles al público. El público no debe ser vulnerable a intromisiones por parte de los funcionarios públicos que actúan por cualquier capricho personal, antojo, malicia, favoritismo o propósito distinto de aquel para el que se le confirió el poder» ${ }^{67}$.

La mayoría de los que han examinado detenidamente la normativa y las directrices gubernamentales coinciden en que el mensaje que rodea al confinamiento ha sido muy confuso. Las directrices entran en conflicto con los reglamentos y con las orientaciones adicionales publicadas por varios cuerpos de seguridad y policía. Los distintos ministros del gobierno también han dado consejos incoherentes a la ciudadanía ${ }^{68}$. En nuestra opinión, es urgente consolidar las orientaciones y crear un sitio web específico que permita a las personas comprobar lo que está permitido y lo que no. Sin embargo, también somos conscientes de que es bastante difícil determinar de antemano todos los casos en los que hay una causa justificada para salir de casa y que sobrepasa la capacidad actual de las fuerzas policiales para establecer líneas de investigación específicas para cada supuesto. Para la mayoría, el mensaje de quedarse en casa ha calado. Pero hay una minoría para la que la idea del confinamiento es extraordinariamente difícil de asimilar y que considera que las orientaciones no son claras ni precisas. Si se presentara una demanda de la HRA en virtud del artículo 8, tendría éxito únicamente basándose en el motivo de legalidad.

Dejando a un lado el problema de lo «prescrito por la ley», la siguiente cuestión, a la hora de determinar la justificación de una injerencia en los derechos, es si la injerencia es necesaria. Aunque es difícil generalizar, para la mayoría de las personas, la injerencia en los derechos es necesaria para la protección de los derechos de los demás ${ }^{69}$. Como se explica en la primera parte de este trabajo, el confinamiento, en el contexto de una situación excepcional de pandemia, es una medida adoptada para que el Estado cumpla su deber positivo del artículo 2, proteger la vida. Sin embargo, para algunos, el confinamiento no es proporcional al objetivo que se persigue. También puede violar un derecho absoluto, como el artículo 3 (prohibición de tortura y de penas o tratos inhumanos o degradantes) o el propio artículo 2, cuando la amenaza a la vida que se plantea es más grave que la amenaza a la vida contra la que protege el confinamiento. En los siguientes apartados se examinan algunos de los ejemplos que han surgido hasta la fecha. Lo más probable es que broten más a medida que la situación evolucione, por lo que la siguiente enumeración no debe considerarse un listado definitivo.

67 R. (Gillan) $v$ Commissioner of Police for the Metropolis [2006] UKHL 12 at [34].

68 Véase el informe de la Comisión Mixta de Derechos Humanos op.cit.

69 Para que sea «necesaria», deben darse razones pertinentes y suficientes para justificar la restricción; la restricción debe corresponder a una necesidad social apremiante; y la restricción debe ser proporcionada al objetivo legítimo que se persigue. 


\section{Violencia doméstica}

Desde que entró en vigor el confinamiento domiciliario, se ha producido un aumento espectacular de los incidentes de violencia doméstica denunciados en el Reino Unido. El 4 de abril de 2020 se informó de que más de 25 organizaciones que ayudan a las víctimas de violencia doméstica «han informado de un aumento en su número de casos desde el comienzo de la epidemia de coronavirus en el Reino Unido» ${ }^{70}$. El 9 de abril de 2020, Refuge, la mayor organización benéfica del Reino Unido de apoyo a las mujeres y los niños contra la violencia doméstica informó de un aumento del $700 \%$ en el tráfico a la página web del Servicio Asistencial Nacional de Ayuda contra el Abuso Doméstico que dirige. Esto fue a raíz de un impulso de los medios de comunicación para asegurarse de que las mujeres supieran que podían acceder a la ayuda durante el confinamiento ${ }^{71}$. El 15 de abril de 2020 se informó de que, desde que se impuso esta medida limitadora de la libertad, los activistas habían identificado al menos 16 presuntos asesinatos de violencia doméstica ${ }^{72}$.

El artículo 3 del CEDH protege contra los tratos inhumanos y degradantes y el Estado tiene el deber positivo de evitarlos y proteger contra ellos ${ }^{73}$. Como ya se ha comentado, el artículo 2 del CEDH impone al Estado la obligación positiva de proteger contra un riesgo real e inmediato para la vida. El hecho de poder salir de casa «para evitar o escapar de un riesgo de lesión o daño» ya se reconoce como una causa justificada en las directrices del gobierno ${ }^{74}$. No obstante, la magnitud del problema es tal que el gobierno también ha lanzado una campaña para ayudar a estas víctimas: «Estar en casa no debería significar estar en riesgo» y ha proporcionado orientaciones específicas sobre el apoyo a las víctimas de abuso y violencia doméstica ${ }^{75}$. A pesar de ello, es necesario hacer mucho más, incluyendo una financiación adecuada para garantizar la eficacia de la campaña y una financiación de emergencia para asegurar que las organizaciones benéficas que apoyan a las víctimas puedan continuar su trabajo.

\section{Discriminación-impacto negativo desproporcionado}

Como ya se ha señalado, el confinamiento es una injerencia en los derechos a la vida privada y familiar (artículo 8), a la libertad religiosa (artículo 9), a la

70 Townsend, M., «Domestic abuse cases soar as lockdown takes its toll», The Guardian, 4 de abril de 2020 .

71 https://www.refuge.org.uk/refuge-sees-700-increase-in-website-visits/

72 Grierson, J., «Domestic abuse killings 'more than double' amid COVID-19 lockdown», The Guardian, 15 de abril de 2020.

73 In re E (a child) [2008] UKHL 66.

74 https://www.gov.uk/government/publications/coronavirus-outbreak-faqs-what-you-can-andcant-do/coronavirus-outbreak-faqs-what-you-can-and-cant-do

75 https://www.gov.uk/government/publications/coronavirus-COVID-19-and-domestic-abuse/ coronavirus-COVID-19-support-for-victims-of-domestic-abuse 
libertad de expresión (artículo 10) y a la libertad de reunión (artículo 11), entre otros. Para la mayoría, esta medida es necesaria y proporcionada, dado el número de vidas que están en juego. Pero, como ocurre con todas las injerencias y limitaciones genéricas en los derechos, hay personas para las que no resulta ser proporcionada, pues, dadas sus circunstancias personales, sufren un impacto desproporcionado y negativo. Mientras que para estas personas es posible argumentar, por ejemplo, que la injerencia en la vida privada no logra un equilibrio justo entre sus propios derechos y la protección del derecho a la vida de los demás, una vía jurídica alternativa se abre al utilizar el artículo 14 del CEDH, que protege contra la discriminación en el ejercicio y disfrute de los derechos reconocidos en el Convenio.

En la aplicación del artículo 14, normalmente se utiliza un enfoque estructurado que plantea una serie de preguntas. La más conocida es la lista formulada por Brooke LJ en el asunto Michalak ${ }^{76}$, modificada posteriormente por el Tribunal de Apelación en el asunto Carson ${ }^{77}$. Las preguntas son las siguientes ${ }^{78}$ : (1) ¿Están los hechos incluidos en el ámbito de aplicación de uno o más de los derechos del Convenio? (2) ¿Existe una diferencia de trato entre el demandante y otras personas comparables en lo que se refiere al disfrute de ese derecho? (3) En caso afirmativo, ¿la diferencia de trato se debe a uno o varios de los motivos prohibidos por el artículo 14? (4) ¿Estaban esas otras personas en una situación análoga o comparable? (5) ¿Era la diferencia de trato objetivamente justificable en el sentido de que tenía una finalidad legítima y guardaba una relación razonable de proporcionalidad con dicha finalidad? O, en términos simples, ¿la diferencia de trato entre términos comparables posee una justificación objetiva y razonable que la legitime?

Este marco también se ha empleado en la jurisprudencia más reciente del Tribunal Supremo, incluidas las sentencias en los asuntos DA y Stott ${ }^{79}$.

Con respecto a la primera pregunta, como ya se ha señalado, es probable que los hechos entren en el ámbito de uno o más de los derechos del Convenio (desde el artículo 2 al artículo 11 del CEDH). También existe una diferencia de trato, pero no se trata de una discriminación directa (no tratar igual a los iguales) sino de una discriminación indirecta (no tratar de forma diferente a personas cuya situación es significativamente diferente). Estamos, por tanto, ante una situación

76 Wandsworth London Borough Council v Michalak [2002] EWCA Civ 271, [2003] 1 WLR 617. The questions were first formulated in St Brice v London Borough of Soutbwark [2001] EWCA Civ 1138, [2002] 1 WLR 1537.

$77 R$ (on the application of Carson) $v$ Secretary of State for Work and Pensions [2003] EWCA Civ 797, [2003] 3 All ER 577.

78 Según lo dispuesto por Lord Steyn in $R$ (on the application of S) $v$ Chief Constable of South Yorkshire [2004] UKHL 39, [2004] 1 WLR 2196, [42].

79 R. (DA) v Secretary of State for Work and Pensions [2019] UKSC 21, [2019] 1 WLR 3289; R. (Stott) $v$ Secretary of State for Justice [2018] UKSC 59, [2018] 3 WLR 1831. See also In the Matter of an Application by McLaughlin for Judicial Review [2018] UKSC 48, [2018] 1 WLR 4250. 
en la que una disposición, criterio o práctica aparentemente neutros sitúan a personas con una característica protegida en desventaja particular con respecto a personas que no poseen esa característica protegida. En su sentencia en el asunto $S G^{80}$, Lady Hale explicó el concepto de discriminación indirecta por razón de sexo de la siguiente manera:

En la discriminación indirecta, por definición, las mujeres y los hombres reciben el mismo trato. La medida en cuestión es neutral a primera vista. No está dirigida (necesariamente) a las mujeres ni tiene por objeto tratarlas de manera menos favorable que a los hombres. Los hombres también la sufren. Y, sin embargo, las mujeres se ven afectadas de forma desproporcionada, ya sea porque son muchas más las que se ven afectadas que los hombres, o porque les resulta más difícil cumplirla. Por tanto, lo que hay que justificar es la medida en sí, y no el hecho de que las mujeres se vean afectadas de forma desproporcionada por esta ${ }^{81}$.

El siguiente paso es identificar un motivo de discriminación y, a diferencia de la legislación antidiscriminatoria, el artículo 14 no está limitado en cuanto a los tipos de discriminación que prohíbe. Algunos motivos se establecen en el propio artículo, pero también se prohíbe la discriminación basada en «cualquier otra situación». Los motivos que genera esta lista de numerus apertus son numerosos y pueden incluir a las personas sin hogar, a los padres solteros o madres solteras, a las personas con discapacidad, a los solicitantes de asilo o, en el caso británico, a los residentes en Escocia (a diferencia de los que residen en Inglaterra o Gales).

Como se ha comentado anteriormente, el derecho a la igualdad reconocido en el artículo 14 no es un derecho absoluto y las diferencias de trato pueden encontrarse justificadas por una causa razonable, pero al igual que en el artículo 1 del Protocolo n. ${ }^{\circ} 1$, el artículo 14 no establece objetivos legítimos. En el caso de las medidas tomadas en el contexto de la pandemia del Covid-19, el objetivo sería el cumplimiento del deber de protección de la vida del artículo 2. El siguiente paso sería, pues, determinar si existe o no un vínculo razonable de proporcionalidad entre los medios empleados y el objetivo que se pretende alcanzar $^{82}$. En su sentencia en el asunto Steinfeld ${ }^{83}$, el Tribunal Supremo confirmó que el examen para determinar si concurría una justificación objetiva y razonable en para el artículo 14 era el mismo que el establecido en el asunto Quila, ateniendo a las cuatro preguntas básicas: «(a) ¿Es el objetivo legislativo (objetivo legítimo) lo suficientemente importante como para justificar la limitación de un derecho fundamental? (b) ¿Las medidas que se han diseñado para cumplir dicho objetivo están directamente relacionadas con el mismo? (c) ¿Son las justas y necesarias

80 R. (SG) v Secretary of State for Work and Pensions [2015] UKSC 47.

81 [189].

82 Ghaidan v Godin-Mendoza [2004] UKHL 30, per Lord Nicholls at [18].

$83 R$. (Steinfeld) v Secretary of State for International Development [2018] UKSC 32. 
para lograrlo?; y (d) ¿Logran un justo equilibrio entre los derechos del individuo y los intereses de la comunidad?» ${ }^{84}$.

Con respecto al impacto desproporcionado del confinamiento, ya se han presentado algunos argumentos acertados y se han modificado las directrices gubernamentales sin necesidad de un procedimiento judicial. Por ejemplo, con la advertencia de la interposición de una reclamación, el 8 de abril de 2020 el gobierno confirmó que había modificado las orientaciones correspondientes ${ }^{85}$, para dejar claro que las personas con problemas de salud que les obligaban a salir del domicilio más de una vez al día o a viajar más allá de su municipio, estaban expresamente autorizadas a hacerlo. La reclamación que solicitaba esta aclaración había sido presentada por dos familias con hijos con trastorno del espectro autista cuya condición les obligaban a salir de casa más de una vez al día por su propio bienestar y salud mental ${ }^{86}$.

Otra demanda, aún no resuelta, ha sido presentada por el Good Law Project para establecer el derecho de todos los niños en edad escolar de Inglaterra que reciben enseñanza a distancia a disponer de un ordenador portátil o una tableta y de conexión a Internet en su domicilio ${ }^{87}$.

\section{Restricciones autoimpuestas}

Mientras continuaba el confinamiento domiciliario y el mensaje de permanecer en casa y salvar vidas, también es importante tener en cuenta a aquellos que se tomaron el confinamiento tan en serio que no salieron ni siquiera en situaciones de urgencia para recibir tratamiento médico vital, ni tomaron las medidas necesarias para evitar un daño grave a su salud mental. La Federación de la Policía ha afirmado que había indicios de un aumento de los suicidios durante la primera quincena del confinamiento domiciliario ${ }^{88}$. El 16 de abril se informó de que también había aumentado el número de enfermos graves que murieron en casa porque se resistieron a llamar a una ambulancia o a desplazarse a un centro sanitario: «Las principales organizaciones médicas han expresado su preocupación por el hecho de que algunas personas estén perjudicando inadvertidamente su propia salud, e incluso arriesgando su vida, al rehuir la atención del sistema nacional de

84 [41] Steinfeld ibid quoting from R. (Aguilar Quila) $v$ Secretary of State for the Home Department [2011] UKSC 45, [2012] AC 621 at [45].

85 https://www.gov.uk/government/publications/coronavirus-outbreak-faqs-what-you-can-andcant-do/coronavirus-outbreak-faqs-what-you-can-and-cant-do

86 Véase también BroACH, S., «Why the coronavirus lockdown adjustment for people with disabilities and mental health conditions was the right thing to do». Disponible en: https://www.specialneedsjungle. com/why-lockdown-adjustments-people-disabilities-mental-health-conditions-right-thing/

87 Para más, véase: https://goodlawproject.org/case/children-will-be-left-behind/

88 Robinson, M., «Coronavirus lockdown has led to increase in suicides», The Daily Mail, 6 de abril de 2020 . 
salud. La gente está demasiado asustada para ir al hospital o no quiere aumentar la presión hospitalaria cuando está bajo la mayor presión de su historia con el Covid-19» ${ }^{89}$.

En este sentido, el gobierno se encontró en una situación delicada en tanto que hacer una campaña pública con el mensaje «quédate en casa y salva vidas» como central, aunque estuviera sujeto a excepciones ${ }^{90}$, podría hacer que se pudieran ver en jaque los beneficios para los que se impuso el confinamiento. Al tratarse de un problema grave en el que había vidas en peligro, era necesario un mensaje que dejara más claro que era posible acudir al hospital por otros problemas de salud graves ajenos a las complicaciones provocadas por el Covid-19. Como ha reflejado la experiencia italiana, también era importante que, una vez que se hubieran relajado las medidas limitativas de la libertad personal y el derecho a la libre circulación, se asegurase que el miedo persistente no impidiera que la gente se ocupase de su salud mental y buscase tratamiento médico cuando lo necesitara.

\section{Cierre de negocios y medidas compensatorias}

Por último, es importante considerar las implicaciones en materia de derechos humanos vinculadas a la exigencia de cerrar los locales y negocios no esenciales durante el confinamiento ${ }^{91}$. Hay una serie de derechos humanos implicados, incluido el artículo 8 sobre la vida privada, pero dada la pérdida de ingresos que supone, el más relevante, quizás, sea la afectación al derecho reconocido en el artículo 1 del Protocolo 1 del CEDH, que protege la propiedad. Dado que la propiedad no ha sido confiscada, a efectos del artículo 1 del Protocolo 1, esta medida se caracterizaría como un control o reglamentación sobre el uso de los bienes por razones de interés general ${ }^{92}$. Cualquier otra intromisión en la propiedad de este modo también está cubierta por este derecho.

El derecho reconocido en e 1 artículo 1 del Protocolo 1 tampoco es un derecho absoluto y puede quedar sometido a limitaciones. En su sentencia en el asunto $A x a^{93}$, Lord Reed sostuvo que la justificación de la injerencia debía determinarse de la siguiente manera: «Si se ha comprobado la existencia de una inje-

89 Campbell, D., Marsh, S., y Johnson, S., «Warning as UK coronavirus outbreak leads to sharp rise in deaths at home», The Guardian, 16 de abril de 2020.

90 Como se estableció en la directriz correspondiente: https:/www.gov.uk/government/publications/ full-guidance-on-staying-at-home-and-away-from-others/full-guidance-on-staying-at-home-and-away-fromothers

91 Reglamentos 4-5 sobre protección a la salud, op.cit.

92 See $R v$ Secretary of State for Health, ex p Eastside Cheese Co [1999] 3 CMLR 12 sobre una orden de control de urgencia dictada en relación con un fabricante de quesos a raíz de que un niño enfermara gravemente de E. coli.

93 Axa General Insurance Ltd v Lord Advocate [2011] UKSC 46. 
rencia, es necesario examinar si ésta constituye una vulneración del derecho. Debe demostrarse que la injerencia respeta el principio de legalidad y persigue un objetivo legítimo por medios razonablemente proporcionados al objetivo que se pretende alcanzar. Este último requisito se centra en la cuestión de si se ha logrado un justo equilibrio entre las exigencias del interés general de la comunidad y las exigencias de la protección de los derechos fundamentales del individuo» ${ }^{94}$.

Aquí, como con otros derechos, la justificación se encontraría en el artículo 2 , vinculado a la protección de la vida. Sin embargo, el proceso de justificación procede de forma ligeramente diferente cuando se interpreta el contenido y los límites del artículo 1 del Protocolo 1. En primer lugar, los tribunales muestran una considerable deferencia cuando el asunto afecta a la política social o económica $^{95}$. En segundo lugar, cuando se trata de un control, en lugar de una privación total, del uso de la propiedad, normalmente no se requiere el pago de una indemnización para que la injerencia quede razonablemente justificada. Esto es así incluso si la legislación, en términos generales, afecta a algunas personas más que a otras ${ }^{96}$. Sin embargo, en su sentencia en el asunto Mott ${ }^{97}$, el Tribunal Supremo no determinó si las condiciones de la licencia, impuestas a un pescador de salmón, que limitaban sus capturas equivalían a una privación o a un control, estableciendo que seguía siendo necesario realizar el examen de proporcionalidad. Dada la gravedad y la falta de proporcionalidad del impacto sobre el demandante, siguiendo las conclusiones de los tribunales inferiores, concluyó que debía pagarse una indemnización.

Ya se han anunciado varias medidas de apoyo a las empresas ${ }^{98}$. Queda por ver si éstas cumplen los requisitos del artículo 1 del Protocolo 1 en el contexto actual.

\section{ACCESO A LA INFORMACIÓN}

\section{Derecho de acceso a la información}

El artículo 10 del CEDH protege el derecho a la libertad de expresión. Existe un amplio acervo jurisprudencial dedicado a la interpretación y aplicación de la HRA en el contexto de las libertades informativas. Esta ha sido crucial para los periodistas que han intentado dar la imagen más completa de la

94 Ibid, [108]. See also In the Matter of Recovery of Medical Costs for Asbestos Diseases (Wales) Bill [2015] UKSC 3, [2015] AC 1016 at [45] per Lord Mance.

95 Axa General Insurance, op. cit.

96 R. (Trailer E Marina (Leven) Ltd) v Secretary of State for the Environment [2004] EWCA Civ 1580, [58].

97 R. (Mott) v Environment Agency [2018] UKSC 10. COVID-19

98 https://www.gov.uk/government/collections/financial-support-for-businesses-during-coronavirus- 
gestión del gobierno de la crisis actual. La protección de los denunciantes es también vital ${ }^{99}$ y es importante recordar que la difusión del Covid-19 allende sus fronteras fue, en parte, como consecuencia de la supresión de la libertad de expresión en China ${ }^{100}$.

A medida que se ha ido desarrollando la crisis, el acceso a la información en manos del Estado ha sido cada vez más importante. Sin embargo, cabe apuntar que, en el Reino Unido, el artículo 10 de la HRA no se ha interpretado como un derecho de acceso a la información. A esta conclusión llegó por primera vez el Tribunal Supremo en su sentencia del asunto Sugar ${ }^{101}$. Dos años más tarde, tuvo la oportunidad de reconsiderar su doctrina en el asunto Kennedy $y^{102}$, en la que se argumentó, sobre la base de la jurisprudencia del TEDH, que el artículo 10 confería un derecho positivo a recibir información de las autoridades públicas y una obligación de las autoridades públicas de compartir información, a menos que su ocultación estuviera justificada en virtud del apartado 2 del artículo 10.

La mayoría sostuvo que las declaraciones de la Gran Sala del TEDH sobre el artículo 10 «deben seguir considerándose un principio general válido» y que el artículo 10 no contiene una obligación prima facie de divulgación de todos los asuntos de interés público ${ }^{103}$. Sobre esta cuestión, los Lores Wilson y Carnwath discreparon. Lord Wilson argumentó que el Tribunal Supremo debería haber concluido que un derecho «a exigir a una autoridad pública no dispuesta a revelar información pública puede surgir en virtud del artículo 10» ${ }^{104}$. Aunque parece improbable que el Tribunal Supremo revierta esta línea jurisprudencial a corto plazo, es poco probable que la importancia de desarrollar y consolidar un derecho reforzado de acceso a la información de interés público disminuya en los próximos años ${ }^{105}$.

\section{Control de la desinformación}

La pandemia COVID-19 ha generado una plétora de información falsa. Desde falsas teorías conspiratorias, que vinculaban las redes del $5 \mathrm{G}$ con la pandemia del

99 Letsas, G. y Mantouvalou, V., «Is gagging NHS workers lawful? Coronavirus and freedom of speech» https://uklabourlawblog.com/2020/04/14/is-gagging-nhs-workers-lawful-coronavirus-and-freedom -of-speech-by-george-letsas-and-virginia-mantouvalou/

100 Leung, H., «Whistleblower Doctor Who Sounded Alarm on Coronavirus Dies in China», Time, 7 de febrero de 2020 .

101 Sugar v BBC [2012] UKSC 4.

102 Kennedy $v$ The Charity Commission [2014] UKSC 20.

103 [94], Lord Mance, with whom Lords Neuberger and Clarke agreed, and Lord Toulson with whom Lords Neuberger and Clarke agreed, at [145].

104 [189]. Lord Carnwath at [219].

105 También existe la Ley de Libertad de Información de 2000, pero es poco probable que sea de gran utilidad debido a las numerosas exenciones que contiene. 
Covid-19, hasta curas y remedios caseros y farmacológicos falsos. Estas se han difundido principalmente a través de plataformas y redes sociales no reguladas de propiedad privada, como Facebook y WhatsApp. Así, el gobierno, y otros usuarios, sólo han podido actuar y alertar del problema a posteriori y esperar que se tomen medidas a la mayor brevedad posible, para no seguir difundiendo los bulos. Esto ha tenido cierto éxito hasta la fecha. Se ha informado de que Facebook ha eliminado dos grupos que promovían teorías conspirativas ${ }^{106}$; WhatsApp limitó a sus usuarios en el reenvío masivo y simultáneo de mensajes, impidiendo enviar el mismo texto más de cinco veces; y YouTube prohibió todos los vídeos de teorías conspirativas que relacionaban el Covid-19 con el $5 \mathrm{G}^{107}$.

\section{Falta de publicidad activa por parte del gobierno}

El mensaje del gobierno en relación con temas como las pruebas de detección, las muertes en las residencias, los EPI de los trabajadores del sistema de salud y los límites del confinamiento han sido evasivos y poco claros. Ni siquiera se han hecho públicos los nombres de quienes forman parte del Grupo de Asesoramiento Científico para Emergencias (SAGE, por sus siglas en inglés) del gobierno. El líder del Partido Laborista, Keir Starmer, escribió al gobierno el 14 de abril de 2020, pidiéndole que se comprometiera a establecer los criterios que utilizaría para informar sobre cómo y cuándo pretendía suavizar el estado excepcional en el que se encontraba el Reino Unido; que publicara su estrategia de salida; y que describiera los sectores de la economía y los servicios públicos básicos que probablemente verían suavizadas las restricciones hasta la fecha impuestas. En el momento de redactar este trabajo, no ha habido ninguna respuesta, aparte del comentario del Secretario de Estado de Sanidad, Matt Hancock, que expresó su frustración por tener que explicar la estrategia de salida. La opinión generalizada del momento era que, en realidad, no existía un plan de salida ${ }^{108}$.

Como ya se ha señalado, el artículo 10 no confiere ningún derecho de acceso a la información de interés público. Sin embargo, otros derechos del Convenio contienen garantías procesales, incluidos los derechos al respeto de la vida privada y familiar protegidos por el artículo 8. En determinadas circunstancias, esto puede otorgar un derecho de acceso a la información en posesión de una autoridad pública. En su sentencia en el caso Hardy y Maile contra el Reino Unido ${ }^{109}$, que de 2020 .

106 Cuthbertson, A., «Dangerous conspiracy theories still spreading», The Independent, 15 de abril

107 Kelion, L., «Coronavirus: YouTube tightens rules after David Icke 5G interview», BBC News, 7 de abril de 2020 .

108 MAson, R., «UK needs lockdown exit strategy, says key coronavirus adviser», The Guardian, 16 de abril de 2020 .

109 ECtHR, n. ${ }^{\circ}$ de recurso 31965/07, 14 de febrero de 2012. 
versaba sobre la regulación de actividades peligrosas (riesgos y daños sobre el medio ambiente) y a la difusión de la información pertinente, el TEDH sostuvo lo siguiente: «El Tribunal ha indicado anteriormente que el respeto a la vida privada y familiar en virtud del artículo 8 exige que, cuando un Gobierno emprenda actividades peligrosas que puedan tener consecuencias adversas ocultas para la salud de las personas que participan en dichas actividades, y cuando no se planteen consideraciones de seguridad nacional, se establezca un procedimiento eficaz y accesible que permita a dichas personas recabar toda la información pertinente y adecuada» ${ }^{110}$.

En las circunstancias de este caso, y a la vista de los numerosos estudios y las medidas gubernamentales adoptadas en relación con el desarrollo de dichas actividades, el Tribunal concluyó que las autoridades habían proporcionado la información requerida por el artículo 8 y que existía un procedimiento efectivo y accesible mediante el cual los demandantes podían buscar cualquier otra información pertinente y adecuada, si así lo deseaban ${ }^{111}$. Aunque un deber similar no quedaría legitimado en el momento álgido del confinamiento, no es difícil imaginar que pudiera surgir en un futuro próximo, si no se proporciona información sobre una estrategia de salida.

Por último, como se ha comentado anteriormente, también existen las obligaciones de investigación previstas en los artículos 2 y 3 . Si bien estas obligaciones estatales no suelen aplicarse para garantizar el acceso a la información a corto plazo, en las circunstancias actuales una investigación ordenada por un tribunal sobre cuestiones como la ausencia de equipos de protección personal adecuados para el personal del sistema de salud y otros trabajadores esenciales en primera línea frente al virus, así como la ausencia de pruebas de detección podría exponer la toma de decisiones del gobierno a un escrutinio público muy necesario.

\section{SUSPENSIÓN DEL CONFINAMIENTO: VIGILANCIA Y PRIVACIDAD}

En el momento de redactar este trabajo, se informó que era probable que se aprobara una prórroga del confinamiento domiciliario de tres semanas, pero sin ninguna estrategia de salida. A pesar de ello, según la experiencia de otros países y el consejo de los expertos recabados, será necesario realizar pruebas y algún tipo de rastreo de contactos. El 16 de abril, la profesora Helen Ward afirmaba en The Guardian, lo siguiente: « ¿Y ahora qué? Una vez más, la experiencia en materia de salud pública, incluida la elaboración de modelos, conduce a

110 [246] citing McGinley and Egan $v U K$, n. ${ }^{\circ}$ de recurso 21825/93, 28 January 2000 and Roche $v U K$, n. ${ }^{\circ}$ de recurso $32555 / 96,19$ de octubre de 2005.

111 [249]. 
algunas recomendaciones muy claras. En primer lugar, encontrar los casos positivos en la comunidad, así como en los hospitales y las residencias, aislarlos y rastrear sus contactos utilizando una combinación de equipos locales de salud pública y herramientas digitales. En segundo lugar, hay que conocer la epidemia. Hay que seguir la epidemia a nivel nacional y local utilizando la vigilancia del NHS, la salud pública y la vigilancia digital para ver dónde siguen propagándose los casos. Esto será esencial para poder empezar a levantar el bloqueo, mientras se protege a la población de los focos de transmisión. También se debe fomentar la resiliencia de la comunidad proporcionando apoyo local a las personas vulnerables afectadas por el virus y el impacto negativo de las medidas de control. En tercer lugar, garantizar la supresión de la transmisión en los hospitales, las residencias y los lugares de trabajo, mediante los equipos de protección adecuados, las pruebas, el distanciamiento y la higiene. Investigar los efectos diferenciales en los grupos étnicos negros y minoritarios, y proporcionar la protección adecuada. En cuarto lugar, garantizar que los más vulnerables, social y médicamente, estén plenamente protegidos mediante el simple acceso a una renta básica, derechos para los inmigrantes y seguridad para los afectados por la violencia doméstica».

Ya se está planteando la preocupación por la injerencia en la intimidad que será necesaria para facilitar el levantamiento del confinamiento estricto ${ }^{112}$. El artículo 8 del CEDH protege el derecho al respeto de la vida privada. La obtención, conservación y divulgación del tipo de información necesaria supondrá una clara injerencia en la vida privada, incluida la información de carácter privado y datos de carácter personal (historiales médicos, su ubicación, sus contactos) y la autonomía (el control de la información que concierne a la persona). Sin embargo, el artículo 8 tampoco es un derecho absoluto y pueden quedar legitimadas algunas limitaciones a su ejercicio por diversas razones, entre ellas los derechos de los demás (derecho a la vida del artículo 2 ) y el bienestar económico del país ${ }^{113}$. Hay una necesidad acuciante de volver a poner en marcha la economía, al menos de forma limitada. Un informe de la Oficina de Responsabilidad Presupuestaria advertía que la economía del Reino Unido podría caer un 35 por ciento antes de junio de $2020^{114}$.

La justificación de las injerencias en la vida privada para facilitar el levantamiento de las medidas más restrictivas a la libertad personal debe ser «conforme a la ley», o, en otras palabras, debe estar «prescrito por la ley». Este aspecto de la

112 Véase, por ejemplo, SELINGER, E., «The lasting privacy and civil liberties impacts of responses to COVID-19». Disponible en: https://www.oecd-forum.org/users/386048-evan-selinger/posts/65529-the-lastingprivacy-and-civil-liberties-impacts-of-responses-to-COVID-19

113 Artículo 8(2).

114 https:/obr.uk/efo/economic-and-fiscal-outlook-march-2020/ Numerous claims have been made about the various violations of human rights, including deaths, which will result from a recession but at this point, the evidence for such claims is not clear. 
legalidad del artículo 8 es una herramienta vital para el TEDH, que lo ha utilizado para dar forma a la perspectiva basada en los derechos humanos ante la proliferación de bases de datos estatales y otras medidas de vigilancia ${ }^{115}$. Las medidas también deben ser necesarias y, sobre esta cuestión, en su sentencia en el caso Marper contra el Reino Unido, la Gran Sala del TEDH sostuvo lo siguiente: «La protección de los datos personales tiene una importancia fundamental para que una persona pueda disfrutar de su derecho al respeto de la vida privada y familiar, garantizado por el artículo 8 del Convenio. El derecho interno debe ofrecer las salvaguardias adecuadas para evitar cualquier uso de los datos personales que pueda ser incompatible con las garantías de este artículo [...] La necesidad de tales salvaguardias es aún mayor cuando se trata de la protección de datos personales sometidos a un tratamiento automatizado, especialmente cuando dichos datos se utilizan con fines policiales. El derecho interno debe garantizar, en particular, que dichos datos sean pertinentes y no excesivos en relación con los fines para los que se almacenan; y que se conserven en una forma que permita la identificación de los interesados durante un período no superior al necesario para los fines para los que se almacenan [...] El derecho interno también debe ofrecer garantías adecuadas de que los datos personales conservados están protegidos eficazmente contra el uso indebido [...] Las consideraciones anteriores son especialmente válidas en lo que respecta a la protección de las categorías especiales de datos más sensibles» ${ }^{116}$.

Con la reanudación del Parlamento el 21 de abril de 2020, es de vital importancia que se empiece a trabajar cuanto antes en la redacción del marco jurídico adecuado y compatible con los derechos humanos, incluyendo una consulta lo más amplia posible.

$* * *$

TITLE: Human Rights and the COVID-19 Pandemic in the United Kingdom

ABSTRACT: The note proceeds two overarching issues examined at the outset: the possibility of changing the protection of the HRA through a derogation from the ECHR; and the impact of the many facets of the protection contained in Article 2 ECHR, the right to life.

RESUMEN: Este trabajo aborda dos cuestiones generales: la posibilidad de modificar la protección de la Ley de Derechos Humanos mediante una derogación del CEDH; y el impacto de las múltiples facetas de la protección contenida en el artículo 2 del CEDH, a saber, el derecho a la vida.

KEY WORDS: human rights, COVID-19, pandemic, United Kingdom.

Palabras Clave: derechos humanos, COVID-19, pandemia, Reino Unido.

FECHA DE RECEPCión: 21.06.2021 FECHA DE ACEPTACIÓN: 20.09.2021

115 Tribunal Europeo De Derecho Humanos, Personal data protection, febrero 2020 https://www.echr. coe.int/Documents/FS_Data_ENG.pdf

116 [103]. 